\title{
Euler-Lagrange Modeling of entrained flow gasification of coke-biomass slurry mixture
}

\author{
Peter Mtui \\ College of Engineering and Technology, University of Dar es Salaam, P. O. Box 35131, Dar es Salaam, Tanzania
}

Email address:

plmtui@yahoo.com

\section{To cite this article:}

Peter Mtui, Euler-Lagrange Modeling of Entrained Flow Gasification of Coke-Biomass Slurry Mixture. American Journal of Energy Engineering. Vol. 1, No. 4, 2013, pp. 43-50. doi: 10.11648/j.ajee.20130104.11

\begin{abstract}
An Euler-Lagrange CFD method for co-gasification simulation of slurry mixture of pulverized petroleum coke and up to $20 \%$ biomass (wheat straw) in a pressurized entrained flow gasifier is proposed to increase the biomass contribution to green electricity generation. The gas phase is modeled as a continuum and the solid phase is modeled by a Discrete Phase Modeling (DPM) using a soft sphere approach for the particle collision dynamic. The model takes into account detailed gas phase chemistry, modeling of the pyrolysis and gasification of each individual particle, particle shrinkage, and heat and mass-transfer between the gas phase and the dispersed phase. The coke was blended with 5-20\% wheat straw on mass basis. The effect of the percentage of biomass blended with coke on the flow field, gas and temperature distribution, syngas composition and particles trajectories are presented. Most important result is the quality and quantity of syngas produced when blended up to $20 \%$ biomass is similar to that of coke gasification. Additional observation is that the reactivity of coke was greatly improved by the presence of biomass. The overall conclusion of this his study is that co-gasification is possible provided that operation is properly adapted.
\end{abstract}

Keywords: CFD, Co-Gasification, Syngas, Coke, Biomass, Slurry

\section{Introduction}

Biomass fuels an important source considered renewable and environmentally friendly which has recently spurred interest to mitigate global warming and the limited fossil resources such as coke and coal. Co-gasification of biomass in entrained coke gasification is one of options currently undertaken.

Despite the long tradition of utilizing the combustible fuel gas from gasification of solid fuels, there still is a lack of detailed scientific knowledge about the complex interactions between the gasification reactions and the fluid dynamics of entrained flow gasifiers.

In order to improve the gasification efficiency and syngas composition, numerous mathematical models for coal and biomass gasification in fluidized beds have been developed. For example, one-dimensional models have been reported by Radmanesh [1] and the more complex Euler-Lagrange models Zhou [2] and Rong [3]. Simpler models such as equilibrium models are suitable for design optimization of gasifiers. Lathouwers [4] considered more comprehensive Euler-Euler modeling approach that considers particulate phase with interpenetrating and interacting with the gaseous phase in reacting fluidized beds. Agrawal [5] reported that the Euler-Euler models allow a relatively realistic description of the time dependent processes in non-reacting.

Euler-Lagrange models are more targeted towards fundamental investigations of the chemical and fluidized bed flows (Zhou, [2]). In Euler-Lagrange models, the trajectory and the state of each individual particle is tracked in space and time by integrating the equations of motion, energy, and mass for each particle in the system. For dense particle system with multiple contacts between particles the soft-sphere the Discrete Phase Model is usually applied. Therefore, the Euler-Lagrange approach potentially offers the most accurate description not only of the particle motion (translational and rotational, particle-particle collisions) but also of chemical reactions and heat and mass transfer between the dispersed phase and the gaseous.

\subsection{Model Description}

Co-gasification of coke and biomass is modeled in a two-stage industrial entrained flow gasifier. The shape of the two stage gasifier is based on the work reported by Bockelie, et al [6] for an industrial gasifier consuming 3000 
tons per day. Figure 1a illustrates a similar two-stage gasifier used in this work that contains three levels of symmetrically placed injectors. The upper level injectors are oriented opposed each other and only water slurry of coke-biomass is introduced. The two bottom levels of injectors are oriented tangentially to create strong swirl flow where water slurry of coke-biomass introduced to the gasifier. Oxygen is also introduced at the two bottom levels. Figure $1 \mathrm{~b}$ illustrates the computed particle flow path in the gasifier.

As for fuel properties, the proximate and ultimate analyses of the coke are taken from the work of Furimsky [7] and for wheat straw biomass from Chunggen [8] which are contained in Table 1. Except for biomass co-firing, the gasifier process conditions and other necessary data such as wall boundary conditions were those reported by Bockelie, et al. [6]. A $1.6 \mathrm{~m}$ diameter 10 meter high pressurized entrained flow gasifier shown in Figure 1 was modeled using the CFD software Fluent [9]. The model results presented in this work were validated against the work of Bockelie, et al [6] who performed coal gasification in a similar pressured entrained flow gasifier.

\section{The Governing Conservative Equations}

The mathematical modeling of the fluid flow is based on a set of coupled conservation governing equations of mass, momentum, energy, and chemical species, similar to Ferziger, et al. [10] and Chung [11]. Properties of fluid (density, the viscosity, the specific heats, the molecular diffusivity, the thermal conductivity, the radiation properties etc.) are given as a function of the state variables.

\subsection{Mass Conservation}

The continuity equation is a mass balance states that the overall mass of the gaseous phase system is conserved. The gas phase conservation equation of mass can be written as:

$$
\frac{\partial \rho}{\partial t}+\frac{\partial}{\partial x_{i}}\left(\rho u_{i}\right)=S_{m}
$$

where $S_{m}$ is the mass source term which accounts for the mass transfer from solids (or liquid) phase to the gas phase.

\subsection{Momentum Conservation}

The Navier-Stokes equation for the conservation of momentum can be written as:

$$
\frac{\partial(\rho u)}{\partial t}+\frac{\partial}{\partial x_{i}}\left(\rho u_{i} u_{j}\right)=-\frac{\partial p}{\partial x_{i}}+\frac{\partial \tau_{i j}}{\partial x_{j}}+\rho F_{i}
$$

where $F_{i}$ is the sum of all external forces (in our case it is only gravity) and $\tau_{i j}$ is the viscous stress tensor is given by as:

$$
\pi_{i j}=\mu\left(\frac{\partial u_{i}}{\partial x_{j}}+\frac{\partial u_{j}}{\partial x_{i}}\right)-\frac{2}{3} \mu \delta_{i j} \frac{\partial u_{l}}{\partial x_{l}}
$$

where the molecular viscosity $\mu$ is introduced, depending on the fluid properties and $\delta_{i j}$ is the Kronecker symbol.

\subsection{Species Conservation}

The conservation equation of chemical species can be written as follows:

$$
\frac{\partial\left(\rho Y_{a}\right)}{\partial t}+\frac{\partial}{\partial x_{i}}\left(\rho u_{i} Y_{a}\right)=\frac{\partial}{\partial x_{i}}\left(\frac{\mu}{S c_{a}} \frac{\partial Y_{a}}{\partial x_{j}}\right)=S_{a}
$$

for $n$ number of species, $a=1, \ldots . n$. The Schmidt number of the species $a$, defined as:

$$
S c_{a}=\frac{\mu}{\rho D_{a}}
$$

\subsection{Energy Conservation}

The conservation equation of energy can be written as:

$$
\frac{\partial(\rho h)}{\partial t}+\frac{\partial}{\partial x_{i}}\left(\rho u_{i} h\right)=\frac{\partial \tau_{i j}}{\partial x_{j}}+\frac{\partial q_{i}}{\partial x_{i}}+\rho u_{i} F_{i}+S_{h}
$$

where $h$ is the total specific enthalpy and for a multicomponent medium it takes the following form:

$$
h=\sum Y_{i} h_{i}
$$

where $Y_{i}$ is the mass fraction of species $i$ in the mixture and $h_{i}$ is the total enthalpy defined as:

$$
h_{i}=h_{r e f, i}+\int_{T_{r e f}}^{T} C p_{i}(T) d T
$$

where ${ }^{0}$ ref,i and $C p_{i}(T)$ is the enthalpy of formation and the specific heat at a constant pressure, for species $i$. The reference temperature is given by $T_{r e f}$.

\section{Turbulent Modeling}

Turbulence gaseous phase is expressed with k- $\varepsilon$ twoequation model in which the solution of two separate transport equations allows the turbulent velocity and length 
scales to be determined independently. The general form of the governing equations for the gas phase is given as follows:

$$
\begin{gathered}
\left.\frac{\partial}{\partial x_{i}}\left(\rho u_{i} k\right)=\frac{\partial}{\partial x_{i}}\left(\frac{\mu_{e}}{\sigma_{k}} \frac{\partial k}{\partial x_{i}}\right)+G-\rho \varepsilon\right) \\
\frac{\partial}{\partial x_{i}}\left(\rho u_{i} \varepsilon\right)=\frac{\partial}{\partial x_{i}}\left(\frac{\mu_{e}}{\sigma_{\varepsilon}} \frac{\partial k}{\partial x_{i}}\right)+\frac{\varepsilon}{k}\left(C_{1} G-C_{2} \rho \varepsilon\right)
\end{gathered}
$$

where $\rho$ is the fluid density, G represents the generation of turbulence kinetic energy, $C_{1}$ and $C_{2}$ are constants, $\sigma_{k}$ and $\sigma_{\varepsilon}$ are the turbulent Prandtl numbers for $k$ and $\mathcal{E}$ respectively.

\section{Particle Trajectory}

In addition to solving transport equations for continuity, momentum, energy, turbulence kinetic energy and dispersion of species, the dispersed second phase is simulated in a Lagrangian frame of reference where the trajectory of the particles is calculated by integrating the force balance of particles.

$$
\frac{d u_{p}}{d t}=F_{D}\left(u-u_{p}\right)+\frac{g\left(\rho_{s}-\rho\right)}{\rho_{s}}+F_{x}
$$

where $F_{D}\left(u-u_{p}\right)$ is the drag force per unit particle mass and is defined as

$$
F_{D}=\frac{18 \mu}{\rho_{s} D_{p}^{2}} \frac{C_{D} \operatorname{Re}_{p}}{24}
$$

where $u$ and $u_{p}$ is the velocity for gaseous phase and particle velocity, respectively.

\section{Chemistry}

The chemistry of gasification and combustion solid carboneous fuel is modeled in three stages, namely: volatilization, solid phase and gaseous phase reactions.

\subsection{Devolatilization}

The evolution of volatile gases from solid carboneous fuel is accounted for using the single rate devolatilization model. The single rate model similar to Badzioch and Hawksley [12] assumes that the rate of devolatilization is first-order and dependent on the amount of volatiles remaining in the particle.

$$
\frac{d m_{p}}{d t}=-k\left[m_{p}-\left(1-f_{v, 0}-f_{w, 0}\right) m_{p, 0}\right]
$$

where $m_{p, 0}$ is the initial particle mass $(\mathrm{kg}), m_{p}$ is the instantaneous particle mass $(\mathrm{kg}), f_{v, 0}$ is the fraction of volatiles initially present in the particle, and $f_{w, 0}$ is the mass fraction of devolatilizing material. The Arrhenius rate constant $k\left(\mathrm{~s}^{-1}\right)$ is given as:

$$
k=A \exp (-E / R T)
$$

There exists extensive literature on the kinetics if devolatilization and gasification. A simple case during volatilization, one assumes a single step process where the volatile matter in the coke and biomass undergo thermal decomposition shown in equation (5.3) where $\alpha_{i}$ is the stoichiometric coefficients for species $i$. The solid specie (char) undergoes heterogeneous reactions as discussed in Section 5.2.

$F U E L=\alpha_{1} C H A R+\alpha_{2} \mathrm{CO}+\alpha_{3} \mathrm{CO}_{2}+\alpha_{4} \mathrm{CH}_{4}+\alpha_{5} \mathrm{H}_{2}+\alpha_{6} \mathrm{H}_{2} \mathrm{O}$

\subsection{Char Combustion}

Surface char combustion is accounted for using the kinetic/diffusion reaction rate model, which assumes that the surface reaction rate is determined either by kinetics or a diffusion rate. The model of Baum \& Street [13] is used in which the diffusion rate as follows:

$$
R_{1}=C_{1} \frac{\left[\left(T_{p}+T_{\infty}\right) / 2\right]^{0.75}}{D_{p}}
$$

and the kinetic rate

$$
R_{2}=C_{2} \exp \left(-E / R^{*} T_{p}\right)
$$

the above are weighted to yield a char combustion rate:

$$
\frac{d m_{p}}{d t}=-\pi D_{p}^{2} P_{0} \frac{R_{1} R_{2}}{R_{1}+R_{2}}
$$

where $P_{0}$ is the partial pressure of oxidant species in the gas surrounding the combusting particle and the kinetic rate $R_{2}$ incorporates the effects of chemical reaction on the internal surface of the char particle and pore diffusion. In the model, the particle size is assumed to remain constant at time $\Delta t$ while the density is allowed to decrease.

\subsection{Gaseous Phase Combustion}

The combustion chemistry of gaseous phase is modeled using the Mixture Fraction/PDF approach, which simplifies 
the combustion process into a mixing problem. This model involves the solution of transport equations for one or two conserved scalars (the mixture fractions). Therefore, instead of solving individual species transport equations, the thermo-chemical properties of the fluid are derived from the predicted mixture fraction distribution. Since the Mixture Fraction/PDF model does not require the solution of multiple species transport equations it is more computationally efficient than the species transport model.

The present work assumes the coke-biomass volatiles and the char are treated as a two fuel streams. The equilibrium chemistry model is used, which assumes that the chemistry is fast enough for chemical equilibrium to exist. The mixture fraction is written in terms of the atomic mass fraction as

$$
f=\frac{Z_{i}-Z_{i, o x}}{Z_{i, f u e l}-Z_{i, o x}}
$$

where $Z_{i}$ is the elemental mass fraction for species $i$. The subscripts $o x$ and fuel denote the values at the oxidizer and fuel stream inlets respectively. The mixture fraction is a conserved scalar and its value at each of the computational control volume is calculated through the solution of the transport equation for the mean (time-averaged) value of $f$.

$$
\frac{\partial}{\partial t}(\rho \bar{f})+\frac{\partial}{\partial x_{i}}\left(\rho u_{i} \bar{f}\right)=\frac{\partial}{\partial x_{i}}\left(\frac{\mu_{t}}{\sigma_{i}} \frac{\partial \bar{f}}{\partial x_{i}}\right)+S_{m}
$$

The source term, $S_{m}$, is due to mass transfer of reacting coal particles into the gas phase. In addition to solving for the Favre mean mixture fractions, Fluent [9] solves a conservation equation for the mixture fraction variance, $\overline{f^{\prime}, 2}$ which is calculated by the following transport equation:

$$
\frac{\partial}{\partial t}\left(\rho \overline{f^{\prime 2}}\right)+\frac{\partial}{\partial x_{i}}\left(\rho u_{i} \overline{f^{\prime 2}}\right)=\frac{\partial}{\partial x_{i}}\left(\frac{\mu_{t}}{\sigma_{i}} \frac{\partial \overline{f^{\prime 2}}}{\partial x_{i}}\right)+C_{g} \mu_{1}\left(\frac{\partial \bar{f}}{\partial x_{i}}\right)^{2}-C_{d} \rho \frac{\varepsilon}{k} \overline{f^{\prime 2}}
$$

where the constants $\sigma_{t}, C_{g}$ and $C_{d}$ are $0.85,2.86$ and 2.0, respectively [Fluent User Guide, 2009] [9]. Under the assumption of chemical equilibrium all thermo-chemical scalars (species fractions, temperature and density) are uniquely related to the instantaneous fuel mixture fraction.

$$
\phi_{i}=\phi(f)
$$

where $\phi_{i}$ represents the instantaneous species concentration, temperature or density. In a non-adiabatic system, equation (22) is generalized as

$$
\phi_{i}=\phi(f, H)
$$

where $H$ is the instantaneous enthalpy.

The effects of turbulence on combustion chemistry are accounted for by using an assumed shape probability density function approach. The probability density function, $p(f)$, which describes the temporal fluctuations of the mixture fraction, $f$, in the turbulent flow is used to compute the averaged values of variables that depend on $f$.

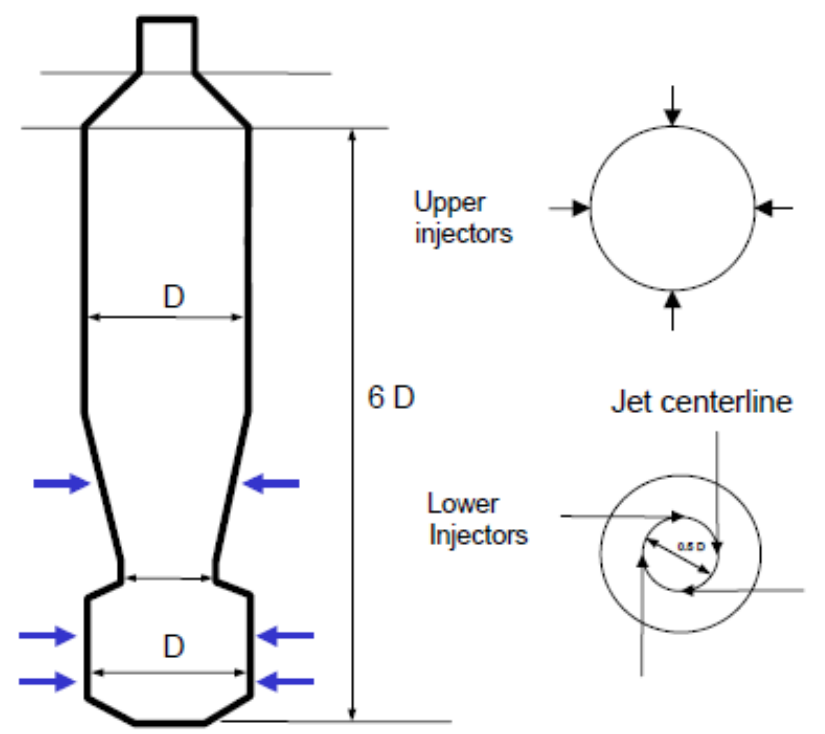

Figure 1a: Two-stage entrained gasifier showing the three levels slurry and oxygen injection.

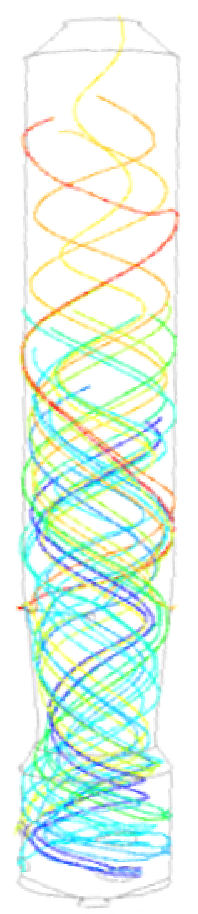

Figure 1b: Computed particle swirling flow path for tangential firing (this work) 
Table 1: Fuels Data [8]

\begin{tabular}{lll}
\hline Proximate analysis (dry basis) & Coke & Wheat Straw \\
\hline Fixed carbon (\%wt) & 89.3 & 15.6 \\
Volatiles (\%wt) & 4.85 & 79.5 \\
Moisture (\%wt) & 0.44 & 7.7 \\
Ash (\%wt) & 5.4 & 4.91 \\
LHV (MJ/kg) & 32.4 & 18.5 \\
Proximate analysis (dry basis) & & \\
C & 82.7 & 47.3 \\
H & 1.72 & 5.68 \\
O & 1.81 & 41.6 \\
N & 1.75 & 0.54 \\
S & 6.78 & $<0.01$ \\
Particle Size Distribution & & \\
Minimum diameter (mm) & 25 & 50 \\
Maximum diameter (mm) & 200 & 1000 \\
Mean diameter (mm) & 110 & 451 \\
Spread parameter [-] & 4.4 & 2.31 \\
\hline
\end{tabular}

Table 2: Reactor geometry and process data [9]

\begin{tabular}{l|ll}
\hline Reactor Data & Diameter $(\mathrm{m})$ & 1.6 \\
& Height $(\mathrm{m})$ & 10 \\
Operating pressure (bar) & 18 \\
Process Data & Coke \& biomass feed rate $(\mathrm{kg} / \mathrm{s})$ & 32.274 \\
& Water flow rate $(\mathrm{kg} / \mathrm{s})$ & 11.188 \\
& Oxidant flow rate $(\mathrm{kg} / \mathrm{s})$ & 23.128 \\
& & \\
Oxidant & Oxygen $(\%)$ & 95 \\
\hline
\end{tabular}

\section{Results and Discussions}

Illustrated in Figure 2 are the contours of the

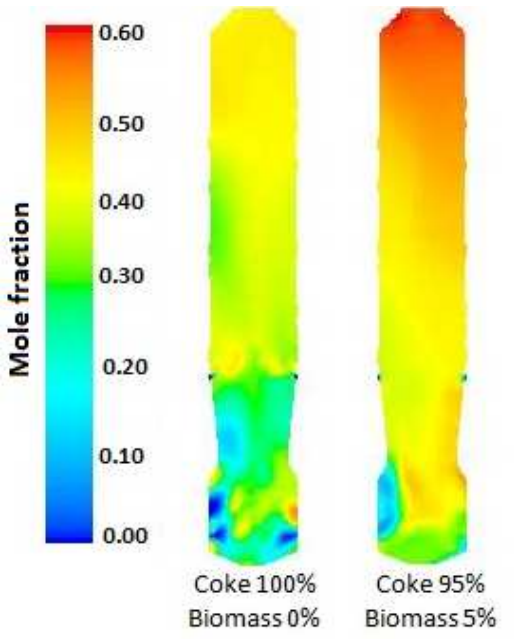

concentration of $\mathrm{CO}$ (mole fraction) along the height of the two-stage entrained flow gasifier. Results indicate higher concentrations of $\mathrm{CO}$ for the biomass substitution in the range of $5 \%$ and $10 \%$. This phenomenon may be explained by the increased reactivity of coke due to the presence of biomass which has higher volatiles content. Figure 3 shows similar trend of increased rate of volatilization as the quantity of biomass substitution is increased to about $15 \%$. Note a second peak in Figure 3 corresponds to the location of slurry injection of at the upper level about $4 \mathrm{~m}$ high as shown in Figure 1a.

Shown in Figure 4 is the rate of char burnout with varying quantities of biomass content. Similar to devolatilization, the char burnout is enhanced by the presence of biomass which is more reactive than coke. Similarly, the second peak corresponds to the location of the upper level injection of slurry. Figure 5 concentration of syngas ( $\mathrm{CO}$ and $\mathrm{H} 2$ ) at gasifier outlet as the biomass content is varied. Results indicate that the $\mathrm{CO}$ and $\mathrm{H} 2$ concentrations are similar for biomass substitution up to $20 \%$. Further, the rate of production of syngas is nearly independent of biomass substitution for the cases studied up to $20 \%$ as shown in Figure 6.

\section{Conclusion}

The gasification of a mixture of petroleum coke and biomass in a 3000 ton/day entrained-flow gasifier has been performed. The characteristics of syngas flow rate, gas composition, heating value, and carbon conversion were determined and compared. The average concentrations of syngas (H2, CO) produced from coke gasification were $43 \%$ and $17 \%$, respectively. In the case of co-gasification, the maximum concentrations of $\mathrm{H} 2$ and $\mathrm{CO}$ were $46 \%$ and $22 \%$, respectively at $10 \%$ biomass blend. These results indicate that the co-gasification of coke-biomass slurry in an entrained-flow gasifier may be an excellent method to efficiently use petroleum coke which has low reactivity.

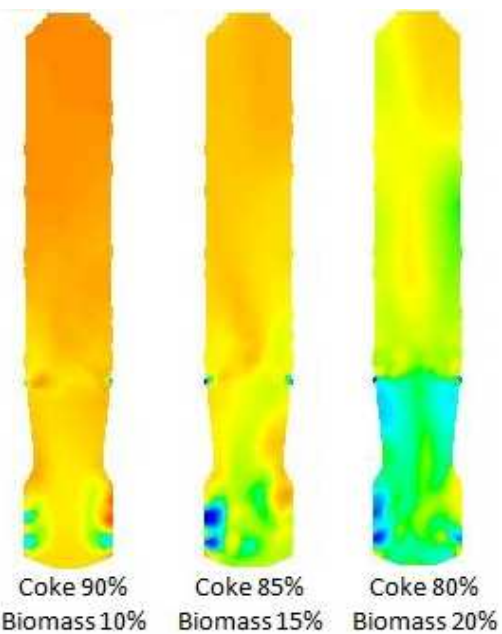

Figure 2: Concentration of $\mathrm{CO}$ along the gasifier height with varying biomass blends 


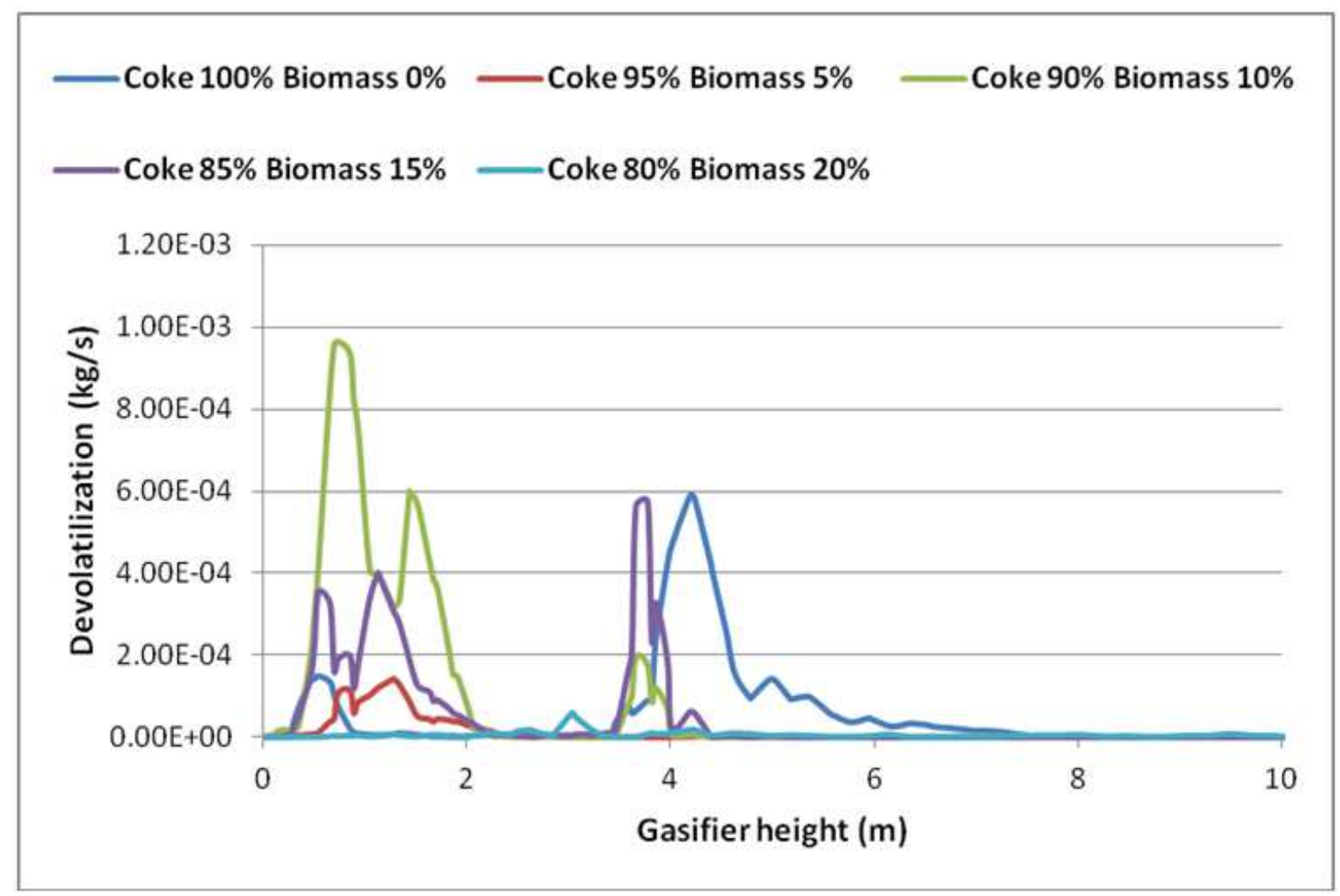

Figure 3: Devolatilization rate along the central axis of the gasifier height

Coke $100 \%$ Biomass $0 \%$ Coke $95 \%$ Biomass $5 \%$ Coke $90 \%$ Biomass $10 \%$

Coke $85 \%$ Biomass $15 \%=$ Coke $80 \%$ Biomass $20 \%$

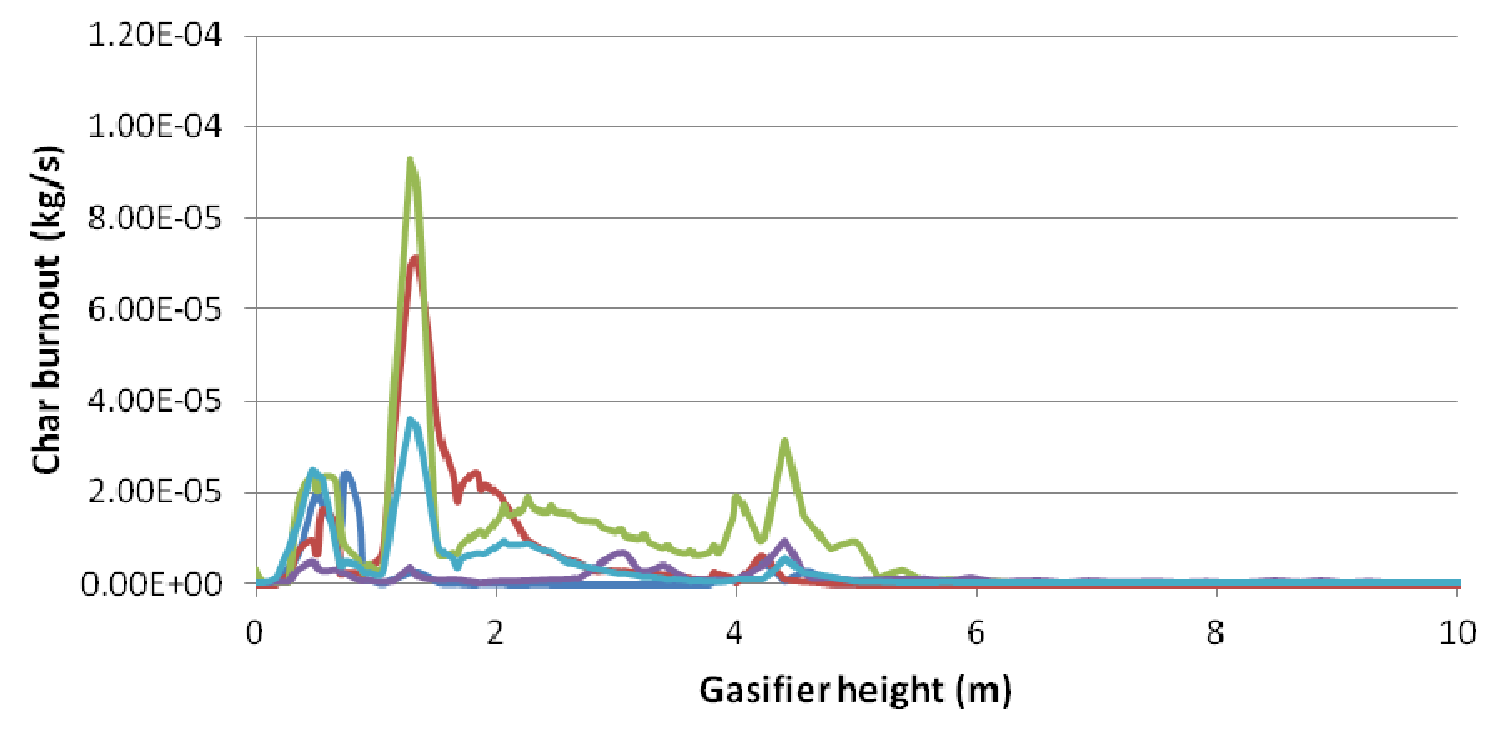

Figure 4: Char burnout rate along the central axis of the gasifier height 


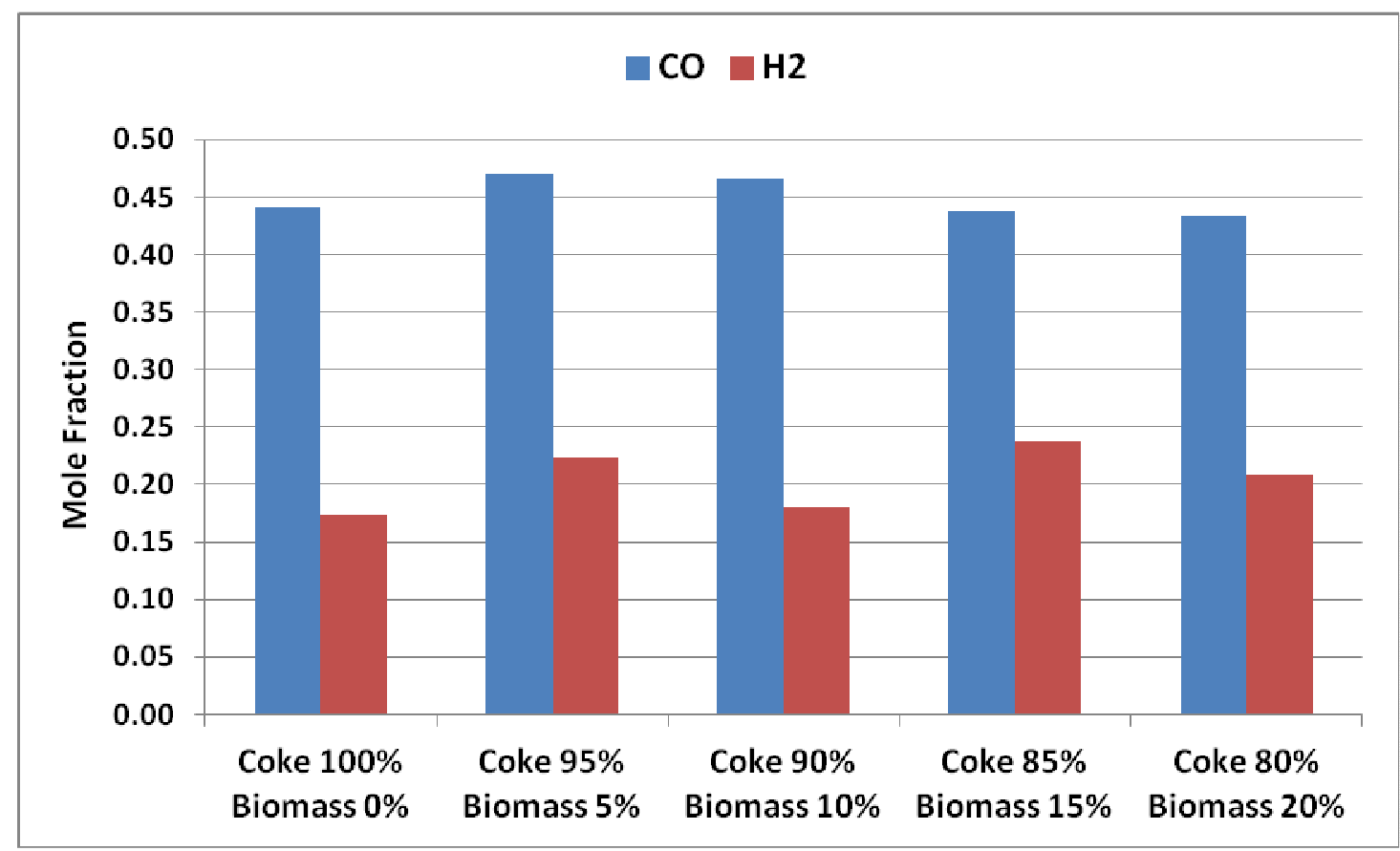

Figure 5: Concentration of syngas (CO and H2) at gasifier outlet

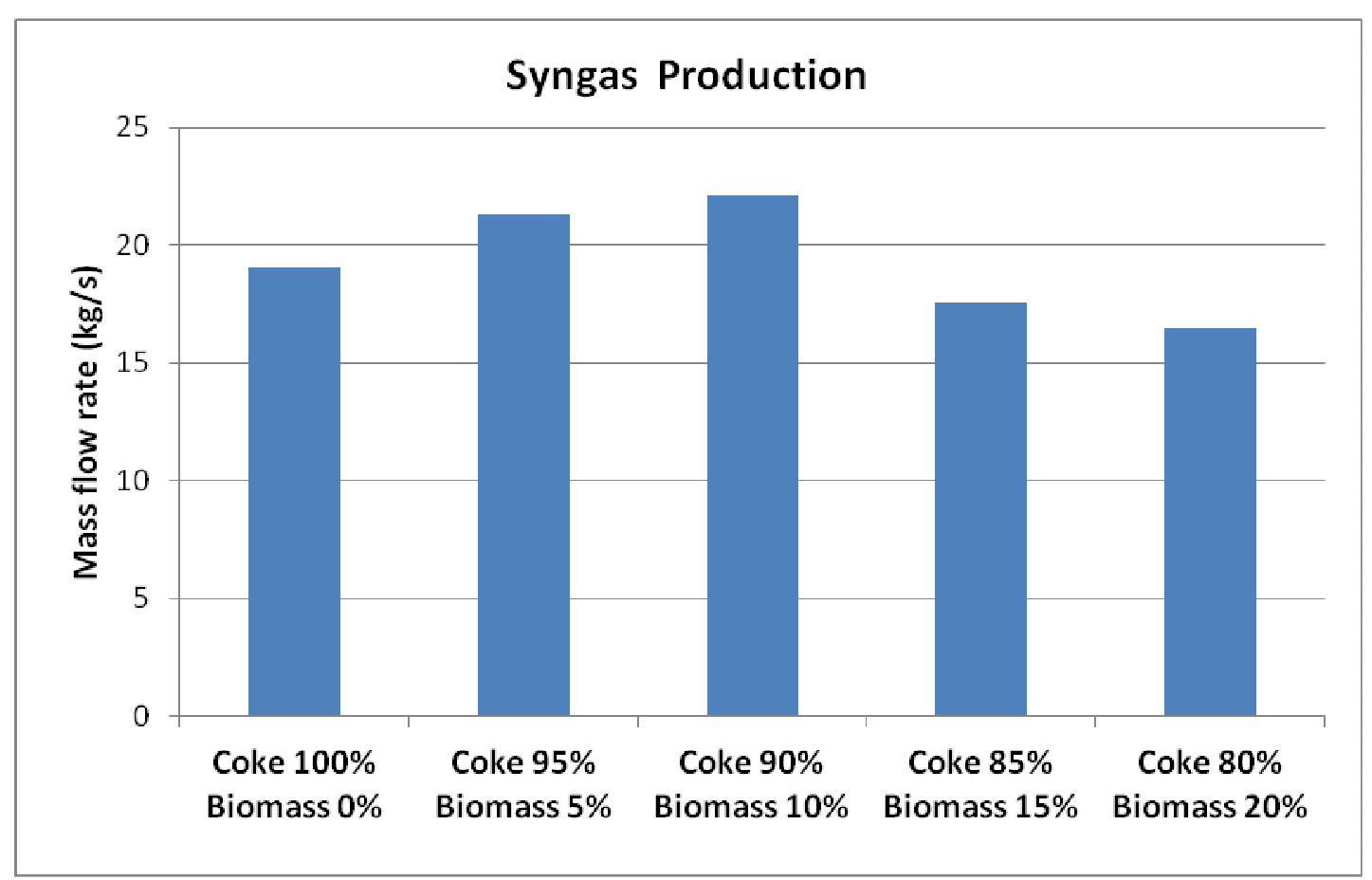

Figure 6: Syngas proaduction rate at the gasifier outlet

\section{References}

[1] Radmanesh, R, J. Chaouki, and C. Guy. Biomass gasification in a bubbling fluidized bed reactor: Experiments and modeling. AIChE Journal, 52(12):4258-4272, 2006.

[2] Zhou H, G. Flamant, and D. Gauthier. DEM-LES of coal combustion in a bubbling fluidized bed. Part I: Gas-particle turbulent flow structure. Chemical Engineering Science, 59:4193-4203, 2004.
[3] Rong D and M. Horio. DEM simulation of char combustion in a fluidized bed. In 3rd Int. Conf. on CFD in the Minerals and Process Industries, pages 469-474. CSIRO, Melbourne, Australia, 1999.

[4] Lathouwers D. and J. Bellan. Modelling of dense gas-solid reactive mixtures applied to biomass pyrolysis in a fluidized bed. Int. J. of Multiphase Flow, 27:2155-2187, 2001.

[5] Agrawal K, Loezos P. N. , Syamlal, M and S. Sundaresan: The role of meso-scale structures in rapid gas-solid flows. J. of Fluid Mechanics, 445:151-185, 2001. 
[6] Bockelie M, Denison M, Chen Z. Linjewile T, Senior C and A. Sarofim: Modeling of Entrained Flow Gasifiers, Gasification Technology Conference 2002, October 27-29, 2002, San Francisco, CA USA

[7] Furimsky, E., Gasification of oil sand coke: Review. Fuel Processing Technology, 1998. 56(3): p. 263-290.

[8] Chunggen Yin, Soren Knudsen, Lasse Rosendahl and Soren Lovmand: Modeling of Pulverized Coal Biomass Co-firing Swirling-Stabilized Burner and Experimental Validation Proceedinds of the International Conference on Power Engineering-09 (ICOPE-9) 16-20, 2009, Kobe, Japan
[9] Fluent 12 User Guide Copyright @2,2009 by ANSYS, Inc.

[10] Ferziger, J. and M. Peric. Computational Methods for Fluids Dynamics. Springer Verlag, 1999.

[11] Chung T. J., Computational Fluid Dynamics. Cambridge University Press, 2002.

[12] Badzioch, S., and Hawksley, P. G. W. (1970). Kinetics of Thermal Decomposition of Pulverized Coal Particles, Ind. Eng. Chem. Process Des. Develop. , 9(4), 521-530.

[13] Baum, M. M., and Street, P. J. (1971). Predicting the Combustion Behaviour of Coal Particles. Combustion Science and Technology, 3(5), 231-243. 